\title{
Plantas medicinais utilizadas pela população atendida no "Programa de Saúde da Família", Governador Valadares, MG, Brasil
}

\author{
Beatriz Gonçalves Brasileiro" ${ }^{1 *}$, Virginia Ramos Pizziolo², Danilo Santos Matos ${ }^{3}$, \\ Ana Maria Germano ${ }^{3}$, Claudia Masrouah Jamal ${ }^{4}$ \\ 'Departamento de Fitotecnia, Universidade Federal de Viçosa, \\ ${ }^{2}$ Departamento de Bioquímica e Biologia Molecular, Universidade Federal de Viçosa, \\ ${ }^{3}$ Departamento de Fitotecnia, Universidade Presidente Antônio Carlos \\ ${ }^{4}$ Departamento de Ciências Farmacêuticas, Universidade Federal do Espírito Santo
}

\section{*Correspondência:}

Beatriz Gonçalves Brasileiro

Departamento de Fitotecnia

Universidade Federal de Viçosa

Avenida Peter Henry Rolfs, s/n

Campus Universitário

Viçosa - MG, Brasil

CEP - 36570-000

E-mail: beatrizgb@vicosa.ufv.br
Este trabalho teve como objetivo realizar um estudo sobre a utilização de plantas medicinais pela população atendida no Programa de Saúde da Família em Governador Valadares, Estado de Minas Gerais, a fim de resgatar, preservar e utilizar este conhecimento em trabalhos com a comunidade. Foi usada a metodologia de questionários pré-estabelecidos, que foram aplicados pelos Agentes de Saúde da Família. O estudo foi feito em 27 bairros da cidade, sendo aplicados 2454 questionários, resultando em 232 plantas citadas como medicinais pela população entrevistada. As principais indicações de uso das plantas medicinais foram como calmante (10\%), contra gripe (18\%) e infecções (9\%). A maioria das plantas utilizadas são preparadas na forma de chá (78\%) e obtidas em cultivo próprio (57\%), sendo que, em geral, o conhecimento sobre o uso e modo de preparo da plantas medicinais foi obtido dos familiares (67\%). A maioria das espécies citadas e utilizadas popularmente possui atividade farmacológica já comprovada na literatura necessitando, entretanto, de orientação correta sobre seu cultivo e emprego terapêutico.

\author{
Unitermos \\ - Plantas medicinais/ \\ utilização \\ - Medicina popular \\ - Fitoterapia
}

\section{INTRODUÇÃO}

O consumo de plantas medicinais tem base na tradição familiar e tornou-se prática generalizada na medicina popular. Atualmente, muitos fatores têm contribuído para o aumento da utilização deste recurso, entre eles, o alto custo dos medicamentos industrializados, o difícil acesso da população à assistência médica, bem como a tendência, nos dias atuais, ao uso de produtos de origem natural (Simões et al., 1998).
Em sociedades tradicionais, a comunicação oral é o principal meio pelo qual o conhecimento é transmitido, e, para que essa transmissão ocorra, é necessário o contato intenso e prolongado dos membros mais velhos com os mais novos. Isto acontece normalmente em sociedades rurais ou indígenas, nas quais o aprendizado é feito pela socialização, no interior do próprio grupo doméstico e de parentesco, sem necessidade de instituições mediadoras. Porém, em comunidades urbanas isto não ocorre. À medida que as gerações vão sendo substituídas, grande parte 
destas informações vai se perdendo, justificando a necessidade do resgate deste conhecimento (Amorozo, 1996). Entretanto, qualquer que seja o esquema de pesquisa com plantas medicinais, o estudo botânico adquire característica fundamental seja no apoio ao levantamento antropológico em comunidades, seja no fornecimento de informações morfológicas e ambientais auxiliando com importantes dados sobre fenologia, tipos de estrutura secretora, hábitos, características morfológicas e identificação das espécies levantadas (Carlini, 1983; Elizabetsky, 1987).

A etnobotânica aplicada ao estudo de plantas medicinais, como vem sendo praticada modernamente, trabalha muito próximo a outras disciplinas correlatas como, por exemplo, a etnofarmacologia. Também a antropologia médica, à medida que contextualiza o uso das plantas, dentro de um "sistema" médico peculiar de um determinado grupo humano, traz sua contribuição ao entendimento da utilização de plantas para fins lucrativos (Amorozo, 1996).

O estudo de plantas medicinais, a partir de seu emprego pelas comunidades, pode fornecer informações úteis para a elaboração de estudos farmacológicos, fitoquímicos e agronômicos sobre estas plantas, com grande economia de tempo e dinheiro. Desta forma, podemos planejar a pesquisa a partir de conhecimento empírico já existente, muitas vezes consagrado pelo uso contínuo, que deverá ser testado em bases científicas.

O Programa Saúde da Família (PSF) foi criado em 1994 pelo Ministério da Saúde, com o principal propósito de reorganizar a prática da atenção à saúde em novas bases e substituir o modelo tradicional, levando a saúde para mais perto da família, melhorando assim a qualidade de vida dos brasileiros. A estratégia do PSF prioriza as ações de prevenção, promoção e recuperação da saúde das pessoas de forma integral e contínua. $\mathrm{O}$ atendimento é prestado na unidade básica de saúde ou no domicílio pelos profissionais (médicos, enfermeiros, auxiliares de enfermagem e agentes comunitários de saúde) que compõem as equipes de Saúde da Família. Assim, esses profissionais, bem como a população acompanhada, criam vínculos de co-responsabilidade, o que facilita a identificação e o atendimento aos problemas de saúde da comunidade. As unidades básicas do programa, funcionando adequadamente, são capazes de resolver $85 \%$ dos problemas de saúde em sua comunidade, ao prestar atendimento de bom nível, prevenindo doenças, evitando internações desnecessárias e melhorando a qualidade de vida da população (Ministério da Saúde, 2006).

Dentro deste contexto, a inclusão da fitoterapia no PSF pode resultar não só em benefícios para a saúde, mas também em benefícios de ordem econômica, conforme relata Noumi et al. (1999). Um aspecto importante desta proposta de tratamento complementar está no fato de que a aplicação deste conjunto de informações torna possível o emprego terapêutico do princípio ativo, sem que seja preciso retirá-lo da planta, evitando, assim, a aplicação dos onerosos processos necessários a sua extração, isolamento e purificação.

Desde a Declaração de Alma-Alta, em 1978, a Organização Mundial da Saúde tem expressado sua posição a respeito da necessidade de valorizar a utilização de plantas medicinais no âmbito sanitário, em função de que $80 \%$ da população mundial depende dessas espécies, no que se refere à atenção primária à saúde (Organização Mundial da Saúde, 1979). Dentro deste contexto, o Brasil tem buscado estabelecer diretrizes na área de plantas medicinais e saúde pública, como a aprovação da Política Nacional de Práticas Integrativas e Complementares no Sistema Único de Saúde (Brasil, 2006).

O presente estudo teve como objetivo o resgate e a valorização do saber popular por meio da obtenção de informações sobre as plantas medicinais utilizadas pela população urbana para, a partir daí, oferecer assistência baseada no conhecimento popular e científico.

\section{MATERIAL E MÉTODOS}

Esta pesquisa foi desenvolvida na cidade de Governador Valadares, situada na Região Leste do Estado de Minas Gerais, que apresenta população de 246.897 habitantes, dos quais 11.016 vivem em área rural do município e 235.881 pertencem à área urbana e estão distribuídos em 70 bairros.

Os dados foram coletados no período de agosto a dezembro de 2002, em 27 bairros atendidos pelo Programa de Saúde da Família, por meio de entrevistas estruturadas (Martin, 1995), com o emprego de um questionário pré-estabelecido.

Foram entrevistados homens e mulheres, escolhidos ao acaso, que após a explicação da natureza e finalidade do trabalho, aceitavam participar da pesquisa. Os questionários foram aplicados pelos Agentes de Saúde da Família, nas visitas às casas e também aos moradores que freqüentavam os postos de atendimento do PSF. As categorias/ aspectos analisados foram: perfil do usuário; utilização de plantas medicinais; razões; forma de aquisição e informações sobre as plantas medicinais.

Foram aplicados 2454 questionários, e os dados obtidos foram tabulados e analisados utilizando-se a estatística descritiva, de modo a fornecer medidas sobre os resultados em relação ao uso de plantas medicinais. Os dados foram apresentados em valores de porcentagem nas diversas categorias analisadas. 


\section{RESULTADOS E DISCUSSÃO}

A partir do levantamento realizado, foi possível traçar o perfil da população estudada, cuja idade variou dentro da seguinte proporção: 4,97\% (122) tinham entre 15 a 19 anos, 16,95\% (416) de 20 a 29 anos, 20,66\% (507) de 30 a 39 anos, $18,59 \%$ (456) de 40 a 49 anos, $16,05 \%$ (394) de 50 a 59 anos e $22,78 \%$ (559) tinham acima de 60 anos. Com relação à escolaridade, $22,37 \%$ (549) eram analfabetos, $56,40 \%$ (1384) freqüentaram o ensino fundamental, $19,20 \%$ (471) freqüentaram o ensino médio e apenas $2,04 \%$ (50) da população amostrada apresentou formação superior.

Quanto à utilização das plantas medicinais, os resultados mostraram que $36,47 \%$ ( 895 pessoas) dos entrevistados utilizam com freqüência, 55,47\% (1361 pessoas) utilizam raramente e apenas $8,06 \%$ (198 pessoas) não utilizam. O uso de plantas medicinais ocorre de forma mais acentuada entre a população mais velha, conforme mostra a Figura 1. Este fato retrata menor atenção da população mais jovem quanto ao conhecimento transmitido através das gerações, mesmo que pessoas desta faixa etária tenham acesso à escolaridade. De acordo com Medeiros et al. (2004), os meios modernos de comunicação causam a perda da transmissão oral do conhecimento sobre o uso de plantas, o que reforça a importância de trabalhos que resgatem o conhecimento etnofarmacológico da população mais velha, conforme comenta Alexiades (1996), bem como a necessidade de conscientizar a população mais jovem com relação a esse tipo de informação.

Entre as pessoas que utilizam as plantas medicinais com freqüência, $59 \%$ freqüentaram o ensino fundamental, $14 \%$, o ensino médio, $22 \%$ eram analfabetas, e apenas $2 \%$ freqüentaram a universidade. Estudos realizados em países de primeiro mundo demonstram uma prevalência do uso de fitoterápicos e outras terapias complementares entre indivíduos com alto nível de escolaridade e renda (Harnack et al., 2001), o que também tem sido observado nos últimos anos em países em desenvolvimento como o Brasil (Ribeiro et al., 2005). No entanto, a divergência dos resultados obtidos neste trabalho se justifica pelo fato de que a população estudada foi aquela que busca o Sistema Público de Saúde e, portanto, possui menor nível de escolaridade e renda, como observado por Costa e Facchini (1997).

Segundo os dados levantados nesta pesquisa, a maior parte das informações sobre a utilização de plantas medicinais é proveniente da tradição familiar, seguido da opção por um tratamento natural, conforme mostrado na Figura 2. Segundo Sacramento (2001), a fitoterapia no Brasil sobreviveu devido às raízes profundas na consciência popular que reconhece sua eficácia e legitimidade. O conhecimento proveniente de gerações anteriores deve ser conservado, entretanto, é importante ressaltar que as pessoas que detêm este conhecimento são aquelas com idade

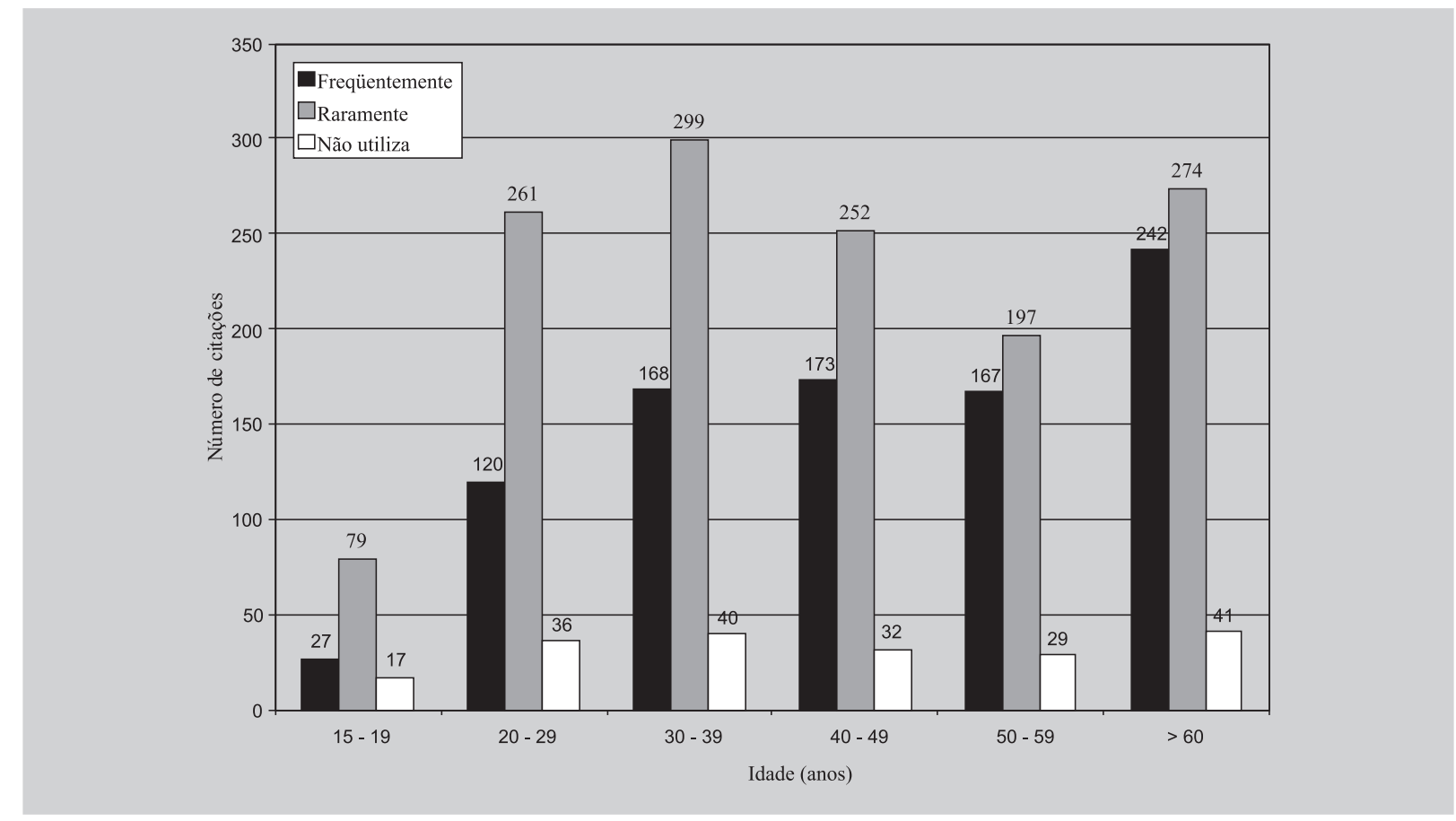

FIGURA 1 - Freqüência de utilização de plantas medicinais de acordo com a faixa etária da população, nos bairros atendidos pelo Programa de Saúde da Família, Governador Valadares, MG (ago-dez/ 2002, n = 2454). 
superior a 60 anos e nível de escolaridade mais baixo, ao passo que as pessoas mais jovens e com melhor nível de escolaridade se mostraram pouco interessadas na fitoterapia.

Entre a população que utiliza freqüentemente as plantas medicinais, 547 pessoas responderam que obtêm as plantas em plantações próprias, conforme mostra a Figura 3. Estes dados mostram que a utilização de plantas medicinais é facilitada pela obtenção das plantas, pois as mesmas são cultivadas pelos próprios usuários e, provavelmente são utilizadas ainda frescas. A facilidade de obtenção e utilização das plantas pela população fica evidente, já que as mesmas geralmente estão disponíveis para consumo imediato.

Outro ponto importante é a manutenção de hortas e quintais, o que contribui com a conservação destas espécies no meio urbano, conforme enfatiza Xolocotzi (1971). A cultura do uso e cultivo de plantas medicinais, em comunidades da periferia, constitui importante recurso local para a saúde e sustentabilidade do meio ambiente urbano (Dias, 2002). Entretanto, é importante a orientação quanto ao cultivo e manejo correto das plantas medicinais, pois a complementação do conhecimento popular e científico sobre a produção e o uso de plantas medicinais é fundamental para sua segurança e eficácia.

O modo de preparo das plantas medicinais para uti- lização no tratamento de doenças é um ponto de grande importância neste estudo visto que daí depende, muitas vezes, a ação terapêutica da planta utilizada. Neste estudo, $78 \%$ das citações (incluindo todas as plantas citadas pelos entrevistados) apontam a preparação na forma de chá como principal meio de utilização das plantas medicinais, conforme a Figura 4. Este processo também foi registrado como o mais usado em trabalho semelhante realizado por Kubo (1997). Os relatos para "chá" incluem a utilização da planta tanto na forma de decocção quanto na forma de infusão.

Foram citadas 232 plantas, sendo que a Tabela I apresenta as 20 plantas mais citadas pela população como medicinais entre a população estudada. A designação do mesmo nome popular para diferentes espécies vegetais dificulta a identificação das plantas utilizadas na medicina caseira, o que ressalta a importância fundamental da coleta e da identificação botânica em trabalhos deste tipo (Penso, 1980). É comum que espécies diferentes tenham o mesmo nome popular dentro de um mesmo bairro, como é o caso da erva cidreira, que foi a planta mais citada neste trabalho, fato também relatado por Somavilla e Canto-Dorow (1996).

A Tabela II apresenta as principais afecções e a indicação de três plantas mais citadas, pela população estudada, sendo que, muitas vezes, várias plantas foram citadas para tratamento de uma mesma afecção.

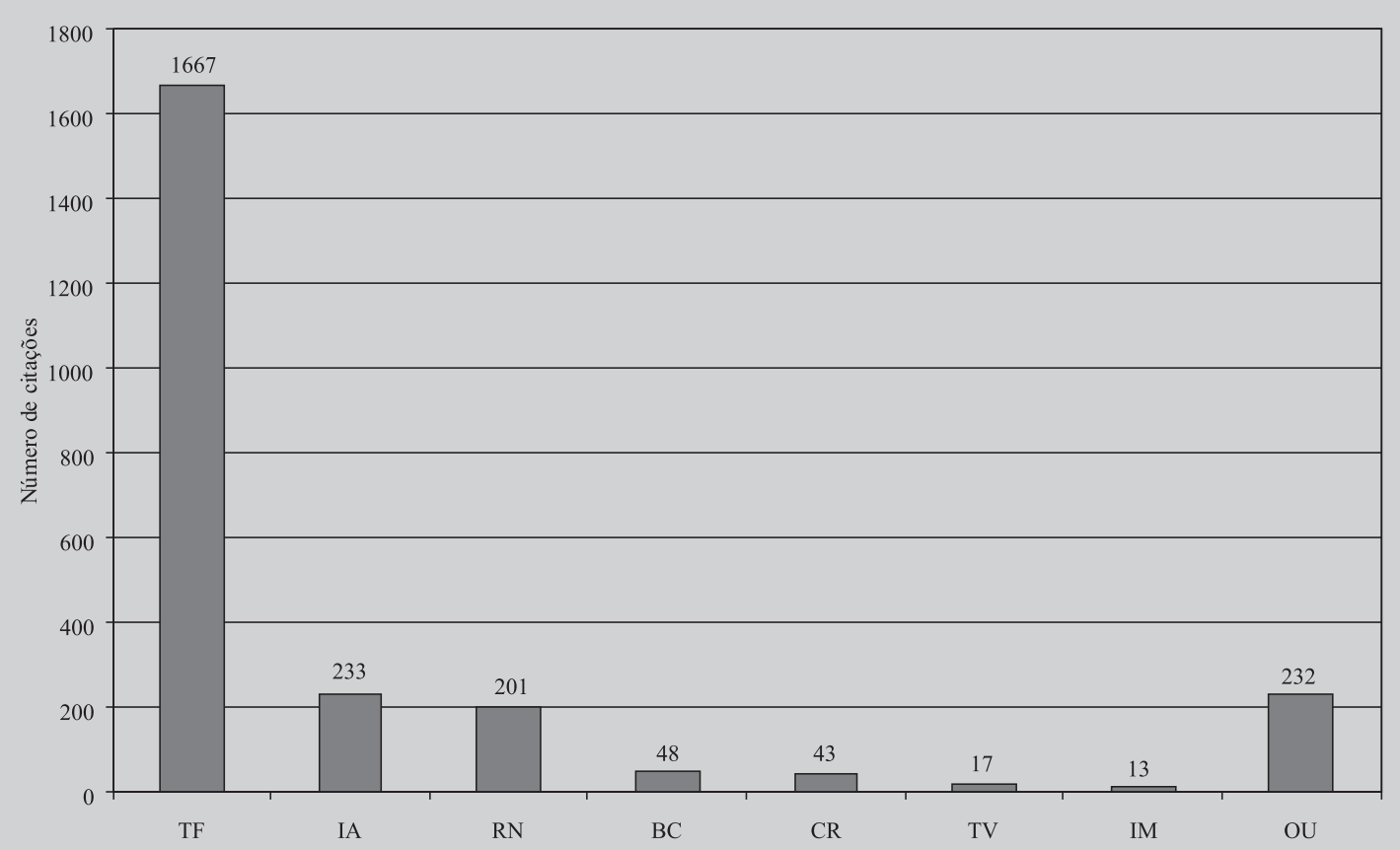

FIGURA 2 - Razões da utilização de espécies medicinais entre a população amostrada, nos bairros atendidos pelo Programa de Saúde da Família, Governador Valadares, MG (ago-dez/ 2002; n =2454). (TF=tradição familiar, IA = influência de amigos, $\mathrm{RN}=$ remédio natural, $\mathrm{BC}=$ Baixo custo, $\mathrm{CR}=$ curiosidade, $\mathrm{TV}=$ propaganda na televisão, $\mathrm{IM}=$ Indicação médica, $\mathrm{OU}=$ outros). 


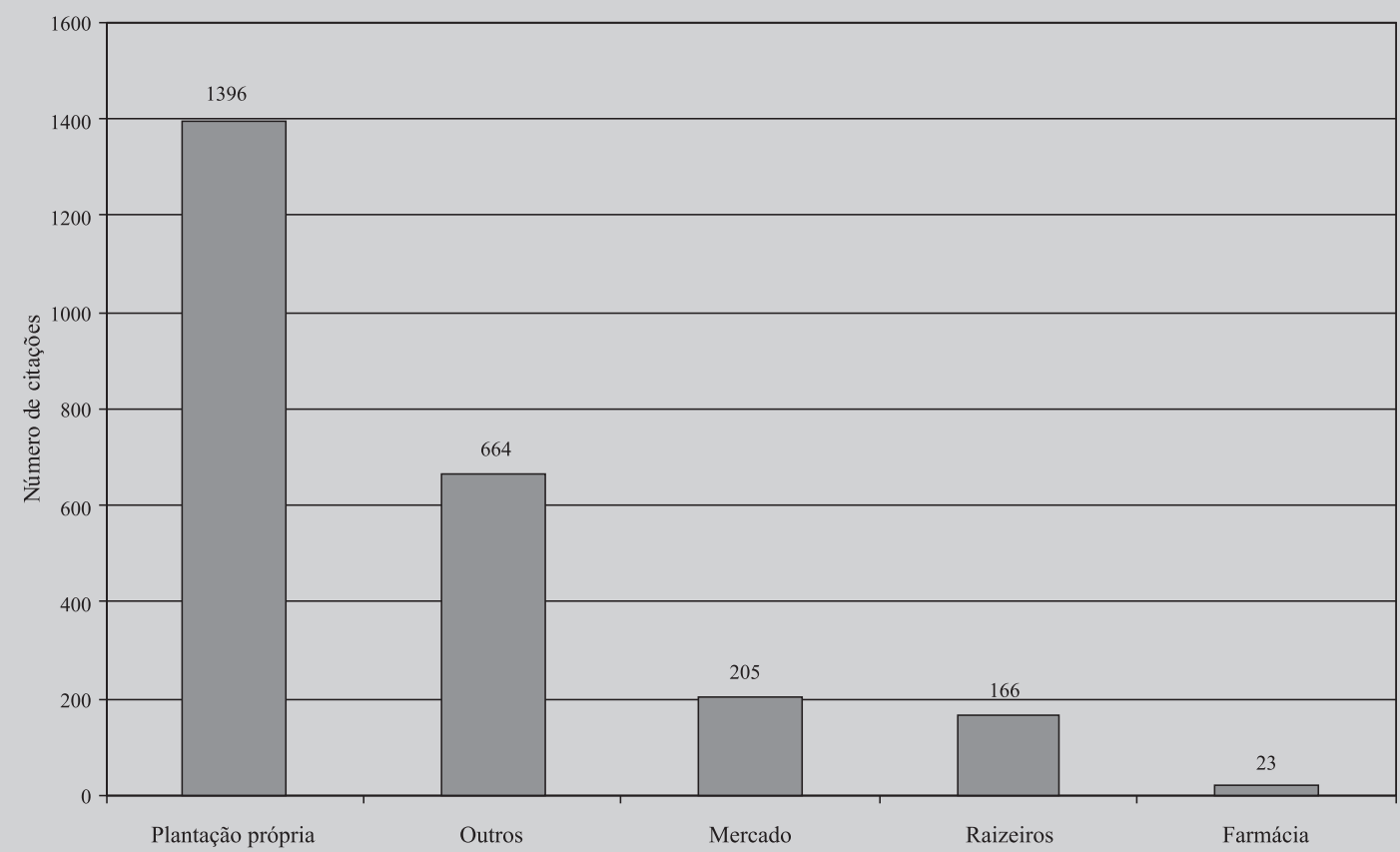

FIGURA 3 - Forma de obtenção das plantas entre a população que utiliza espécies medicinais nos bairros atendidos pelo Programa de Saúde da Família, Governador Valadares, MG (ago-dez/ 2002; n = 2454).

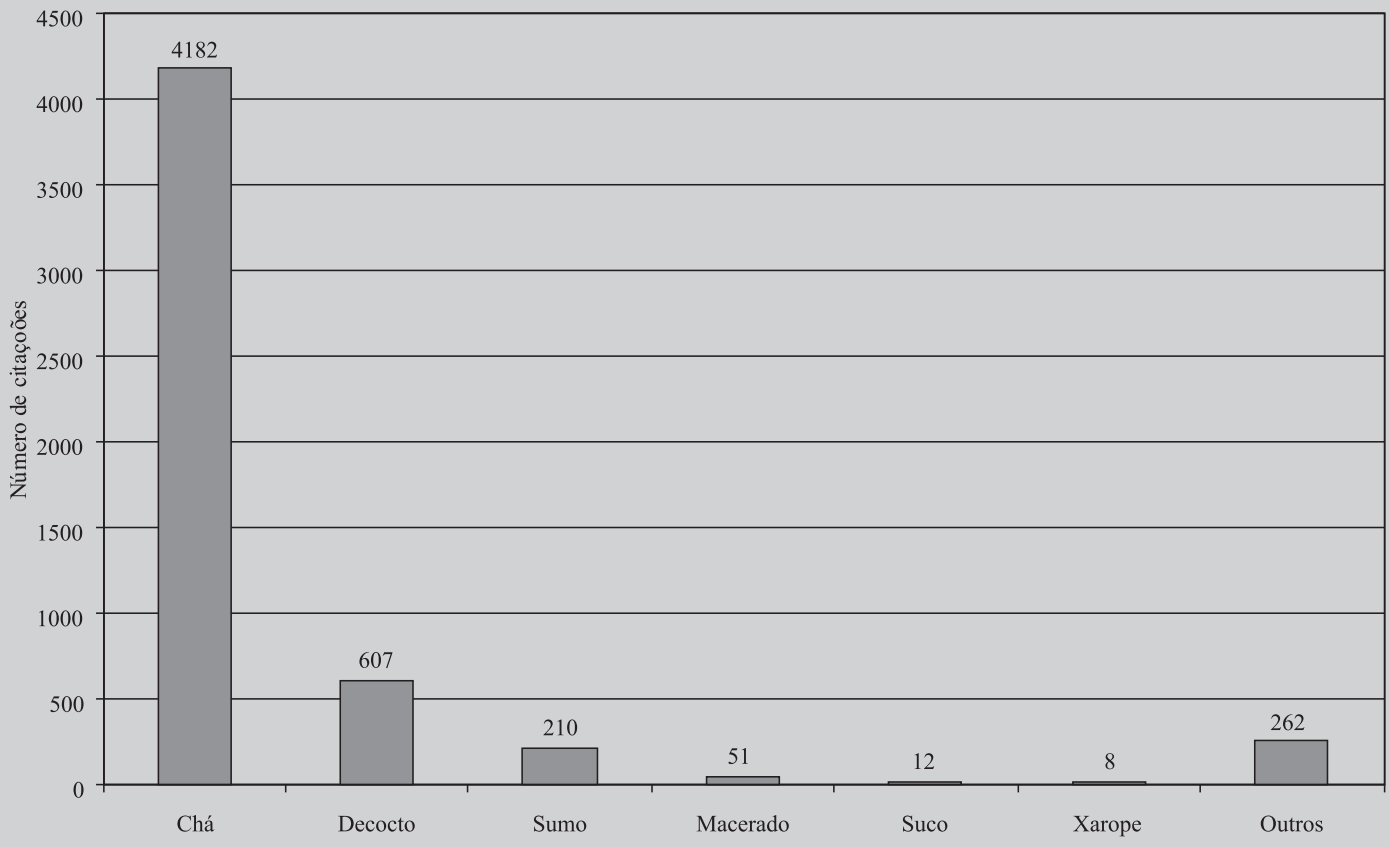

FIGURA 4 - Modo de preparo das espécies medicinais utilizadas pela população dos bairros atendidos pelo Programa de Saúde da Família, Governador Valadares, MG (ago-dez/ 2002; n =2454, podendo cada indivíduo marcar mais de uma alternativa por planta medicinal indicada).

Em muitos casos, a utilização popular confere com a literatura (Lorenzi, Matos, 2002; Martins et al., 2000). Conforme verifica-se na Tabela II, muitas enfermidades primárias, que levam a população a adquirir medicamentos industrializados, com custos elevados, podem ser tratadas com plantas medicinais com custo muito menor. 
TABELA I - Principais plantas utilizadas pela população amostrada nos bairros atendidos pelo Programa de Saúde da Família, Governador Valadares, MG (ago-dez/ 2002)

\begin{tabular}{lccc}
\hline Nome popular & Número de Citações* & Parte da planta utilizada & Preparação \\
\hline Erva-cidreira & 986 & Folhas & Chá. \\
Boldo & 964 & Folhas & Chá, infusão, macerado. \\
Algodão & 636 & Parte aérea & Chá; infusão. \\
Hortelã & 554 & Parte aérea & Chá, infusão, macerado. \\
Poejo & 501 & Parte aérea & Chá, infusão, macerado. \\
Tansagem & 431 & Parte aérea & Chá; infusão. \\
Arnica & 411 & Parte aérea & Chá, infusão, macerado. \\
Camomila & 334 & Parte aérea & Chá, infusão. \\
Folha de laranja & 278 & Folhas & Chá, infusão. \\
Alecrim & 266 & Folhas & Chá, infusão. \\
Saião & 260 & Folhas & Chá, cataplasma, macerado. \\
Hortelã pimenta & 218 & Parte aérea & Chá, cataplasma, macerado. \\
Folha de mamão & 169 & Frutos, Folhas & Chá, macerado, sumo. \\
Cana-de-macaco & 169 & Folhas & Chá, cozido. \\
Quebra-pedra & 177 & Parte aérea & Chá. \\
Picão & 169 & Parte aérea & Chá, cozido, macerado. \\
Erva-doce & 151 & Frutos & Chá, cozido, cataplasma. \\
Romã & 141 & Frutos & Chá, gargarejo. \\
Carqueja & 139 & Parte aérea & Chá, macerado, cozido, sumo. \\
Mangericão & 132 & Parte aérea & Chá, cozido. \\
\hline
\end{tabular}

${ }^{*}$ Cada indivíduo podia citar mais de uma planta medicinal.

TABELA II - Principais afecções e as respectivas plantas medicinais utilizadas pela população dos bairros atendidos pelo Programa de Saúde da Família, Governador Valadares, MG (ago-dez/ 2002)

\begin{tabular}{lcc}
\hline Principais Afecções & Número de citações* & Principais plantas utilizadas \\
\hline Gripe & 1990 & Poejo, Hortelã, Erva-cidreira. \\
Tensão nervosa/ Stresse & 1092 & Erva-cidreira, Camomila, Erva-doce. \\
Lesão/ Infecção & 936 & Algodão, Transagem, Arnica. \\
Diarréia & 645 & Boldo, Mamão, Camomila. \\
Rinites & 606 & Quebra-pedra, Cana-de-macaco, Abacate. \\
Inflamação & 401 & Algodão, Transagem, Arnica. \\
Hipertensão & 365 & Erva-cidreira, Chuchu, Carambola. \\
Dores estomacais & 361 & Boldo, Mamão, Macaé. \\
Analgésico & 321 & Arnica, Guiné, Melão-de-São-Caetano. \\
Hepatoprotetor & 320 & Boldo, Mamão, Picão. \\
Antitussígeno & 311 & Hortelã, Manga, Poejo. \\
Antitérmico & 231 & Camomila, Laranja, Melão-de-São-Caetano. \\
Infecção de garganta & 221 & Romã, Transagem, Gengibre. \\
Vermífugo & 202 & Erva-de-Santa-Maria, Hortelã, Arruda. \\
Colagogo/ Digestivo & 185 & Boldo, Macaé, Mamão. \\
Diabetes & 175 & Pata de Vaca, Carqueja, Insulina vegetal. \\
Cardio - proteção & 170 & Alecrim, Manjericão, Babosa. \\
Dor-de-cabeça & 129 & Boldo, Cordão de Frade, Camomila. \\
Antidiarréico & 123 & Goiaba, Camomila, Boldo. \\
Cólicas & 105 & Erva-doce, Mentrasto, Camomila. \\
\hline
\end{tabular}

* Cada entrevistado podia citar mais de uma planta para o tratamento da mesma afecção. 
Este trabalho reforça a necessidade de se orientar a população quanto à utilização das plantas medicinais que podem ser responsáveis pelo tratamento de muitas doenças primárias, com bons resultados econômicos e de melhoria da saúde da população de baixa renda. Entretanto, este objetivo só poderá ser alcançado a partir de trabalho participativo e bem orientado.

\section{CONCLUSÕES}

A partir dos resultados obtidos, verificamos que, mesmo tratando-se de áreas urbanas, a utilização de plantas medicinais é bastante difundida, sendo que, apenas $8,06 \%$ dos entrevistados não utilizam plantas medicinais. O grande número de plantas citadas neste trabalho (232) reafirma a importância da pesquisa etnobotânica no resgate do conhecimento tradicional, em áreas urbanas, seja pelo seu valor histórico cultural seja pela necessidade de confirmação das indicações de uso.

Espera-se com este trabalho contribuir com proposta de orientação de uso de plantas medicinais no sistema público de saúde.

\section{ABSTRACT \\ Medicinal plants used by the population assisted by the "Programa de Saúde da Família" (Family Health Program) in Governador Valadares County - MG, Brazil}

This study was conducted to evaluate the use of medicinal plants by the population assisted by the "Programa de Sau'de da Familia" in Governador Valadares $-M G$, in order to rescue, preserve and use this knowledge in works carried out with the community. The preestablished questionnaire methodology was used. Those questionnaires were applied by the Family Health Agents. The study was accomplished in 27 residential quarters, as being applied 2454 questionnaires, and 232 plants were mentioned as medicinal ones by the interviewed population. The main indications for using the medicinal plants were: as sedative (10\%), against influenza (18\%) and infections (9\%). Most plants under use are prepared as tea (78\%) and are obtained in own cropping (57\%). In general, the knowledge on the use and preparation of the medicinal plants proceeded from their relatives (67\%). Most mentioned and popularly used species have pharmacological activity already proven in the literature. However, this population needs a correct orientation on their cropping and therapeutic use.

UNITERMS: Medicinal plants/use. Popular medicine. Phytotherapy.

\section{REFERÊNCIAS BIBLIOGRÁFICAS}

ALEXIADES, M. N. Selected guidelines for ethnobotanical research: a field manual. New York: Botanical Garden, 1996. 306p.

AMOROZO, M. C. M. A abordagem etnobotânica na pesquisa de plantas medicinais. In: DI STASI, L. C. Plantas medicinais: arte e ciência. Um guia de estudo interdisciplinary. São Paulo: Editora da Universidade Estadual Paulista, 1996. 230p.

BRASIL. Ministério da Saúde. Portaria n ${ }^{\circ}$ 971, de 3 de maio de 2006. Aprova a Política Nacional de Práticas Integrativas e Complementares no Sistema Único de Saúde. Diário Oficial da União, n.84, seção 1,2006. 19p.

CARLINI, E. A. Pesquisas com plantas medicinais usadas em medicina popular. Rev. Ass. Med. Bras., v.29, p.109-110, 1983.

COSTA J. S. D.; FACCHINI L. A. Utilização de serviços ambulatoriais em Pelotas: onde a população consulta e com que freqüência. Rev. Saúde Públ., v.31, p.360-369, 1997.

DIAS, J. E. A importância do uso de plantas medicinais em comunidades de periferia e sua produção através da agricultura urbana. Acta Hort., v.569, p.79-85, 2002.

ELIZABETSKY, E. Pesquisa em plantas medicinais. Cien. Cult., v.39, p.697-702, 1987.

HARNACK, L. J.; RYDELL, S. A.; STANG, J. Prevalence of use of herbal products by adults in the Minneapolis/St Paul, Minn, metropolitan area. Mayo Clin. Proc., v.76, p.688-694, 2001.

KUBO, R.R. Levantamento das plantas de uso medicinal em Coronel Bicaco, RS. Porto Alegre, 1997. 163p. [Dissertação de Mestrado. Instituto de Biociências Universidade Federal do Rio Grande do Sul].

LORENZI, H.; MATTOS, F.J.A. Plantas Medicinais do Brasil: Nativas e Exóticas. Nova Odessa: Instituto Plantarum, 2002. 512p.

MARTIN, G. J. Ethnobotany: 'a people and plants' conservation manual. London: Chapman \& Hall, 1995. 268 p. 
MARTINS, E. R.; CASTRO, D. M. de; CASTELLANI, D. C.; DIAS, J. E. Plantas medicinais. Viçosa: Editora UFV: Universidade Federal de Viçosa, 2000. 220p.

MEDEIROS, M. F. T.; FONSECA, V.S.; ANDREATA, R.H.P.Plantas medicinais e seus usos pelos sitiantes da Reserva Rio das Pedras, Mangaratiba, RJ, Brasil. Acta Bot. Bras., v.18, p.391-99, 2004.

MINISTÉRIO DA SAÚDE, Departamento de Atenção Básica: Saúde da Família. Disponível em: $<$ www.saude.gov.br/dab/atencaobasica.php $>$.Acesso em 23 jan. 2007.

NOUMI, E.; HOUNGUE, F.; LONTSI, D. Traditional medicines in primary health care: plants used for the treatment of hypertension in Bafia, Cameroon. Fitoterapia, v.70, p.134-139, 1999.

ORGANIZAÇÃO MUNDIAL DA SAÚDE / UNICEF. Cuidados Primários em Saúde. Relatório da Conferência Internacional sobre Cuidados Primários da Saúde, AlmaAta, URSS, 6 a 12 de setembro de 1978. Brasília: Ministério da Saúde, 1979. 64 p.
PENSO, G. The role of WHO in the selection and characterization of medicinal plants (vegetables drugs). $J$. Ethnopharmacol., v.2, p.183-188, 1980

RIBEIRO, A.Q.; LEITE, J.P.V.; DANTAS-BARROS, A.M. Perfil de utilização de fitoterápicos em farmácias comunitárias de Belo Horizonte sob a influência da legislação nacional. Rev. Bras. Farmacogn., v.15, p.6570, 2005.

SACRAMENTO, H. T. Legislação para produção, comercialização e uso de plantas medicinais. In: Jornada Paulista de Plantas Medicinais, 5.; 2001. Botucatu. Anais. Botucatu: UNESP, 2001. p.33.

SIMÕES, C. M. O.; MENTZ, L. A.; SCHENKEL, E. P.; NICOLAU, M.; BETTEGA, JR. Plantas da Medicina Popular do Rio Grande do Sul. 5. ed. Porto Alegre: Editora da UFRGS, 1998. v.1. 150 p.

SOMAVILLA, N.; CANTO-DROW, T.S. Levantamento das plantas medicinais utilizadas em bairros de Santa Maria - RS. Ciência e Natura, v.18, p.131-148, 1996.

XOLOCOTZI, E.H. Exploración etnobotánica y su metodologia. Chapingo: S. A. G., 1971. 188p.

Recebido para publicação em 18 de abril de 2007 Aceito para publicação em 12 de junho de 2008 